\title{
Gender-specific hip fracture risk in community-dwelling and institutionalized seniors age 65 years and older
}

\author{
M. Finsterwald • E. Sidelnikov • E. J. Orav • B. Dawson-Hughes $\cdot$ R. Theiler • A. Egli • \\ A. Platz • H. P. Simmen • C. Meier • D. Grob • S. Beck • H. B. Stähelin • \\ H. A. Bischoff-Ferrari
}

Received: 30 May 2013 / Accepted: 11 September 2013 / Published online: 18 October 2013

(C) International Osteoporosis Foundation and National Osteoporosis Foundation 2013

\begin{abstract}
Summary In this study of acute hip fracture patients, we show that hip fracture rates differ by gender between communitydwelling seniors and seniors residing in nursing homes. While women have a significantly higher rate of hip fracture among the community-dwelling seniors, men have a significantly higher rate among nursing home residents.

Introduction Differences in gender-specific hip fracture risk between community-dwelling and institutionalized seniors have not been well established, and seasonality of hip fracture risk has been controversial.

Methods We analyzed detailed data from 1,084 hip fracture patients age 65 years and older admitted to one large hospital center in Zurich, Switzerland. In a sensitivity analysis, we extend to de-personalized data from 1,265 hip fracture patients from the other two large hospital centers in Zurich within the same time frame (total $n=2,349$ ). The denominators were person-times accumulated by the Zurich population
\end{abstract}

M. Finsterwald · E. Sidelnikov · A. Egli $\cdot$ D. Grob ·

H. A. Bischoff-Ferrari

Centre on Aging and Mobility, University Hospital Zurich and City

Hospital Waid, Zurich, Switzerland

E. J. Orav

Department of Biostatistics, Harvard School of Public Health,

Boston, MA, USA

B. Dawson-Hughes

USDA Human Nutrition Research Center on Aging,

Tufts University, Boston, MA, USA

R. Theiler

Department of Rheumatology, Triemly City Hospital Zurich,

Zurich, Switzerland

A. Platz

Department of Traumatology, Triemly City Hospital Zurich,

Zurich, Switzerland in the corresponding age/gender/type of dwelling stratum in each calendar season for the period of the study.

Results In the primary analysis of 1,084 hip fracture patients (mean age 85.1 years; $78 \%$ women): Among communitydwelling seniors, the risk of hip fracture was twofold higher among women compared with men $(\mathrm{RR}=2.16 ; 95 \% \mathrm{CI}$, 1.74-2.69) independent of age, season, number of comorbidities, and cognitive function; among institutionalized seniors, the risk of hip fracture was $26 \%$ lower among women compared with men ( $\mathrm{RR}=0.77 ; 95 \% \mathrm{CI}$ : $0.63-0.95$ ) adjusting for the same confounders. In the sensitivity analysis of 2,349 hip fracture patients (mean age 85.0 years, $76 \%$ women), this pattern remained largely unchanged. There is no seasonal swing in hip fracture incidence.

Conclusion We confirm for seniors living in the community that women have a higher risk of hip fracture than men. However, among institutionalized seniors, men are at higher risk for hip fracture.

H. P. Simmen

Department of Emergency Medicine and Traumatology,

University Hospital Zurich, Zurich, Switzerland

C. Meier

Department of Traumatology, City Hospital Waid,

Zurich, Switzerland

D. Grob $\cdot$ S. Beck

Acute Geriatric Care, City Hospital Waid, Zurich, Switzerland

H. B. Stähelin

Department of Geriatrics, University Hospital Basel,

Basel, Switzerland

H. A. Bischoff-Ferrari $(\bowtie)$

Department of Geriatrics and Aging Research, University Hospital

Zurich, Gloriastrasse 25, CH-8091 Zurich, Switzerland

e-mail: Heike.Bischoff@usz.ch 
Keywords Dwelling $\cdot$ Gender $\cdot$ Hip fractures $\cdot$ Seasonality

\section{Introduction}

Hip fractures are the most frequent and most severe fractures among seniors age 75 years and older, a rapidly growing segment of the population [1]. By the ninth decade of life, an estimated one in every three women and one in every six men will have sustained a hip fracture [2]. In the first 12 months after hip fracture, $10 \%$ of seniors fracture their other hip, 30 to $50 \%$ are re-admitted to acute care, $50 \%$ are left with permanent functional disabilities, $25 \%$ are admitted to nursing homes, and $10-25 \%$ die [3-7].

Established risk factors for hip fractures include female gender [8-20], older age [21-25], a higher number of comorbidities [26], low cognitive function [27, 28], falls, and osteoporosis [29]. Winter season and residing in a nursing home may also increase the risk of hip fracture risk, but studies have been controversial [14, 30-46].

Regarding type of dwelling, most authors report seniors residing in nursing homes to be at significantly higher risk for hip fracture compared with their community-dwelling counterparts $[21,24,25,47-50]$. But the estimates vary substantially: Hip fracture risk among institutionalized seniors are reported to be 2.2 [24] to 7.6 [25] times higher than their counterparts living at home. This may in part be explained by the fact that seniors residing in nursing homes often carry many of the established risk factors for hip fracture as described above [22]. Few studies investigated the combined effects of gender and type of dwelling on hip fracture risk. Brennan et al. found that women were at higher risk of hip fractures regardless of whether they lived in a nursing home or in the community [21]; on the other hand, Sugarman and colleagues observed that women were at higher risk only when living in the community, and there was no difference in gender-specific hip fracture risk among nursing home dwellers [47]. Butler et al. reported that living in a nursing home was associated with higher risk of hip fracture in both genders, but the increase was more pronounced in men than it was in women [49].

Several studies performed in the United States [30, 36-38, 42], Canada [40], UK [33], Norway [31, 35], Spain [51], Taiwan [41], Hong Kong [32], and Australia [39, 43] reported significant differences in hip fracture risk by seasons with the highest risk observed in winter months. On the other hand, other studies from the same countries [14, 44-46] found no difference in hip fracture risk by season. Mechanistically, it has been suggested that falls due to snow and ice may play an important role in seasonality of fractures $[31,36]$. Thus, one cause of the increased fracture risk in winter compared with summer may be that older persons are more likely to slip and fall during periods of snow and ice [52]. These factors may be particularly important for fracture types that tend to occur outdoors in active older persons [50, 53, 54]. Hip fractures, which mostly occur indoors [55-57], may be less affected by snow and ice, or may occur less in the presence of snow, as suggested in the largest epidemiologic study on the influence of season and weather on fracture risk [30]. Notably, however, hip fracture risk may be indirectly influenced by cold weather, since some studies suggest that susceptibility to falls in seniors increase with hypothermia [55, 58]. Also, vitamin D depletion and less physical activity during winter season may contribute to muscle weakness $[59,60]$ and increase the risk of falls $[61$, 62] and fractures [63] during winter months.

In this study, we aimed to investigate if and to what extend hip fracture rates differ by gender depending on type of dwelling. Furthermore, we investigated if hip fracture incidence varies by season in the Zurich region of Switzerland, where snow and ice are common during the winter season.

\section{Methods}

\section{Participants}

For the primary analysis, we included 1,090 consecutive acute hip fracture patients aged 65 years or older who were admitted to a large hospital center (Triemli City Hospital, Zurich, Switzerland) between January 2005 and March 2010. The data for these patients were acquired in preparation for a clinical trial of early rehabilitation after hip fracture [7]. Each hip fracture patient 65 years or older admitted to the hospital was offered to be interviewed, and over $90 \%$ of them consented to participate. Six of these patients had missing data on type of dwelling before the fracture and were excluded from the analysis, leaving total sample size at 1,084.

In addition, for a sensitivity analysis, de-personalized data on 1,624 acute hip fracture patients admitted to the other two large hospital centers in Zurich (Zurich University Hospital and Waid City Hospital) within the same period were abstracted from the hospital databases. Of these patients, 359 were excluded from the analyses for the following reasons: Four had missing data on type of dwelling prior to the fracture; 355 were transferred from other hospitals, and no further information on their type of dwelling was available in the abstracted data. Thus, for the sensitivity, we added 1,265 acute hip fracture patients with de-personalized data, which resulted in a total number of 2,349 acute hip fracture patients from three large hospital centers in Zurich.

Variables

For the 1,084 acute hip fracture patients included in the primary analysis, demographic and anthropometric characteristics, information on type of dwelling before the index hip 
fracture, fracture date, and comorbid conditions were obtained in an interview or directly from their medical records. The Charlson comorbidity index [64] was applied to account for severity of various comorbid conditions. Cognitive function was assessed with the Mini Mental State Examination during acute care after hip fracture repair [65].

For the de-personalized data set including 1,624 hip fracture patients from the two other large hospital centers in Zurich, available data were restricted to gender, age, fracture date, and type of dwelling prior to admission. For all participants, season when the fracture occurred was derived from the fracture date, and the seasons were defined as follows: winter: December through February; spring: March through May; summer: June through August; and fall: September through November. The shared data of 2,349 seniors included in the sensitivity analysis included gender, age, type of dwelling, and season when the fracture occurred.

\section{Statistical analysis}

Hip fracture patients who lived at home before hospitalization were compared with those admitted from a nursing home with respect to important risk factors using $t$ test for continuous variables and $\chi^{2}$-test for categorical variables as appropriate. Poisson regression models were applied to evaluate associations between the potential risk factors and hip fracture risk. The analyses were based on fracture rates. The numerators of the rates were the sum over the study period of the number of hip fractures that occurred during a particular season among individuals in a particular age/gender/type of dwelling (community-dwelling versus institutionalized) stratum. The denominators were person-times accumulated by the Zurich population in the corresponding age/gender/type of dwelling stratum in each calendar season for the period of the study. Population of Zurich was estimated from the official 2002 population statistics of the City of Zurich; this was the most recent year for which the statistics by age, gender, and type of dwelling were available. Zurich population increased only $4 \%$ between 2002 and 2008 .

The regression model for the primary analysis included type of dwelling, season, age, gender, Charlson comorbidity index, Mini Mental Score as main effect variables, and the interaction term between gender and type of dwelling. Zurich official population statistics do not break down the population by Mini Mental Score or Charlson comorbidity index. In order to adjust for these variables, we calculated mean MMSE score and mean Charlson comorbidity index for each age/gender/ type of dwelling stratum and included these means into the models. For the sensitivity analysis, the regression models adjusted for type of dwelling, season, age, gender, and the interaction term between gender and type of dwelling. All analyses were performed in SASC v.9.2 statistical software
(CopyrightC 2002-2008 by SAS Institute Inc., Cary, NC, USA), and two-sided $p$ value of 0.05 was used for statistical significance.

\section{Results}

Characteristics of the study population

Characteristics of the 1,084 acute hip fracture patients included in the primary analysis are summarized in Table 1. Patients admitted from nursing homes were on average about 4.6 years older (87.9 versus 83.3 years respectively; $p<0.0001)$, had a higher number of comorbidities $(\mathrm{p}=0.01)$, and had a lower cognitive function $(\mathrm{p}<0.0001)$ than those admitted from home (Table 1).

Characteristics of the 2,349 hip fracture patients included in the sensitivity analysis are presented in Table 2 . Including all hip fracture patients from three hospital centers, the pattern stayed the same: Patients admitted from nursing homes were significantly older than seniors admitted from home (87.8 versus 84.3 years, respectively; $p<0.0001$ ). Compared with the primary analysis population, higher proportion of sensitivity analysis participants lived at home prior to their hip fracture (59\% versus $79 \%$, respectively; Tables 1 and 2); in the primary analysis population, however, this proportion did not differ significantly in men and women (Table 2).

Primary analysis of 1,084 acute hip fracture patients

Hip fracture risk in men and women differed significantly by type of dwelling prior to the hip fracture event. Among community-dwelling seniors, hip fracture rates were twice as high in women compared with men $(\mathrm{RR}=2.16,95 \% \mathrm{CI}$, 1.74-2.69) independent of age, season, comorbid conditions, and cognitive function. Conversely, and adjusting for the same covariates, among institutionalized seniors, hip fracture rates were $23 \%$ lower among women compared with men $(\mathrm{RR}=$ 0.77, $95 \%$ CI 0.63-0.95; Table 3, Fig. 1a).

We did not observe any seasonal changes in hip fracture rates. Figure $2 \mathrm{a}$ presents frequencies of hip fractures by weeks of the year; there were no noticeable seasonal patterns. The risk of hip fracture adjusted for type of dwelling, age, comorbid conditions, and cognitive function also did not depend on season and changed very little throughout the year (Table 3).

Age was a strong and independent predictor of hip fracture risk in community dwelling as well as institutionalized seniors, but the strength of this effect differed by the type of dwelling. Among community-dwelling seniors the risk of hip fractures increased more than five times for people age 7584 years $(\mathrm{RR}=5.60 ; 95 \% \mathrm{CI}, 4.42-7.09)$, more than 15 times 
Table 1 Characteristics of acute hip fracture patients included in the primary analysis $(N=1,084)$

\begin{tabular}{ll}
\hline Characteristic & $\begin{array}{l}\text { Type of dwelling before hip } \\
\text { fracture }\end{array}$ \\
\cline { 2 - 2 } $\begin{array}{ll}\text { Home value } \\
(n=650)\end{array}$ & $\begin{array}{l}\text { Nursing/old age } \\
\text { home }(n=434)\end{array}$ \\
\hline
\end{tabular}

\begin{tabular}{|c|c|c|c|}
\hline \multicolumn{4}{|l|}{ Season $(\%)$} \\
\hline Winter & $164(59.4)$ & $112(40.6)$ & \multirow[t]{4}{*}{0.58} \\
\hline Spring & $158(62.2)$ & $96(37.8)$ & \\
\hline Summer & $174(61.5)$ & $109(38.5)$ & \\
\hline Fall & $154(56.8)$ & $117(43.2)$ & \\
\hline \multicolumn{4}{|l|}{ Age (mean, SD), years } \\
\hline Men & $82.1(6.6)$ & $86.6(6.8)$ & $<0.0001$ \\
\hline Women & $83.6(6.8)$ & $88.3(6.3)$ & $<0.0001$ \\
\hline Both genders & $83.3(6.8)$ & $87.9(6.5)$ & $<0.0001$ \\
\hline \multicolumn{4}{|l|}{ Age categories $(\%)$} \\
\hline \multicolumn{4}{|l|}{ Men } \\
\hline $65-74$ & $18(78.3)$ & $5(21.7)$ & \multirow[t]{4}{*}{0.0005} \\
\hline $75-84$ & $74(64.9)$ & $40(35.1)$ & \\
\hline $85-94$ & $42(46.2)$ & $49(53.8)$ & \\
\hline $95+$ & $3(23.1)$ & $10(76.9)$ & \\
\hline \multicolumn{4}{|l|}{ Women } \\
\hline $65-74$ & $55(84.6)$ & $10(15.4)$ & \multirow[t]{4}{*}{$<0.0001$} \\
\hline $75-84$ & $243(75.0)$ & $81(25.0)$ & \\
\hline $85-94$ & $200(51.4)$ & $189(48.6)$ & \\
\hline $95+$ & $15(23.1)$ & $50(76.9)$ & \\
\hline \multicolumn{4}{|l|}{ Both genders } \\
\hline $65-74$ & $73(83.0)$ & $15(17.0)$ & \multirow[t]{4}{*}{$<0.0001$} \\
\hline $75-84$ & $317(72.4)$ & $121(27.6)$ & \\
\hline $85-94$ & $242(50.4)$ & $238(49.6)$ & \\
\hline $95+$ & $18(23.1)$ & $60(76.9)$ & \\
\hline \multicolumn{4}{|l|}{ Gender (\%) } \\
\hline Male & $137(56.9)$ & $104(43.1)$ & \multirow[t]{2}{*}{0.26} \\
\hline Female & $513(60.9)$ & $330(39.1)$ & \\
\hline $\begin{array}{l}\text { Charlson Comorbidity Index } \\
\quad(\text { mean, SD) }\end{array}$ & $2.1(1.9)$ & $2.4(1.7)$ & 0.01 \\
\hline $\operatorname{MMSE}\left(\right.$ mean, SD) ${ }^{\mathrm{c}}$ & $23.5(5.4)$ & $18.3(7.6)$ & $<0.0001$ \\
\hline
\end{tabular}

${ }^{\text {a }}$ Based on $t$ test for continuous variables and $\chi^{2}$ test for categorical variables

${ }^{\mathrm{b}}$ Values on two participants are missing; sample sizes: home $n=649$, nursing/old age home $n=433$, total $N=1,082$

${ }^{\mathrm{c}}$ Values on 415 participants are missing; sample sizes: home $n=469$, nursing/old age home $n=200$, total $n=669$

for seniors 85-94 years old ( $\mathrm{RR}=15.20$; $95 \% \mathrm{CI}, 11.98$ 19.28), and more than 22 times for those age 95+years $(\mathrm{RR}=22.14$; $\mathrm{CI}, 13.57-36.14)$ compared with seniors age 65-74 years (Table 3). In institutionalized seniors, risk of hip fracture also significantly increased with age, but the increase was not as dramatic as in community dwelling
Table 2 Characteristics of acute hip fracture patients included in the sensitivity analysis $(n=2,349)$

\begin{tabular}{|c|c|c|c|}
\hline \multirow[t]{2}{*}{ Characteristic } & \multicolumn{2}{|c|}{ Type of dwelling before hip fracture } & \multirow[t]{2}{*}{$p^{\mathrm{a}}$ value } \\
\hline & Home $(n=1,848)$ & $\begin{array}{l}\text { Nursing/old age } \\
\text { home }(n=501)\end{array}$ & \\
\hline \multicolumn{4}{|l|}{ Season $(\%)$} \\
\hline Winter & $473(79.6)$ & $121(20.4)$ & 0.62 \\
\hline Spring & $460(79.9)$ & $116(20.1)$ & \\
\hline Summer & $456(78.1)$ & $128(21.9)$ & \\
\hline Fall & $459(77.1)$ & $136(22.9)$ & \\
\hline \multicolumn{4}{|c|}{ Age (mean, SD), years } \\
\hline Men & $83.3(7.5)$ & $86.4(6.8)$ & $<0.0001$ \\
\hline Women & $84.6(7.3)$ & $88.1(6.2)$ & $<0.0001$ \\
\hline Both genders & $84.3(7.4)$ & $87.8(6.4)$ & $<0.0001$ \\
\hline \multicolumn{4}{|c|}{ Age categories $(\%)$} \\
\hline \multicolumn{4}{|l|}{ Men } \\
\hline $65-74$ & $64(92.8)$ & $5(7.3)$ & 0.01 \\
\hline $75-84$ & $177(79.4)$ & $46(20.6)$ & \\
\hline $85-94$ & $180(77.3)$ & $53(22.7)$ & \\
\hline $95+$ & $24(68.6)$ & $11(31.4)$ & \\
\hline \multicolumn{4}{|l|}{ Women } \\
\hline $65-74$ & $136(92.5)$ & $11(7.5)$ & $<0.0001$ \\
\hline $75-84$ & $564(85.7)$ & $94(14.3)$ & \\
\hline $85-94$ & $609(72.8)$ & $228(27.2)$ & \\
\hline $95+$ & $94(64.0)$ & $53(36.0)$ & \\
\hline \multicolumn{4}{|l|}{ Both genders } \\
\hline $65-74$ & $200(92.6)$ & $16(7.4)$ & $<0.0001$ \\
\hline $75-84$ & $741(84.1)$ & $140(15.9)$ & \\
\hline $85-94$ & 789 (73.7) & $281(26.3)$ & \\
\hline $95+$ & $118(64.8)$ & $64(35.2)$ & \\
\hline \multicolumn{4}{|l|}{ Gender (\%) } \\
\hline Male & $445(79.5)$ & $115(20.5)$ & 0.60 \\
\hline Female & 1403 (78.4) & $386(21.6)$ & \\
\hline
\end{tabular}

${ }^{\text {a }}$ Based on $t$ test for continuous variables and $\chi^{2}$ test for categorical variables

seniors. Compared with the age group $65-74$ years, the risk increased almost three times for seniors age 75-84 $(\mathrm{RR}=2.78$; $95 \%$ CI, 1.51-5.10), more than four times for people age 85 94 years $(\mathrm{RR}=4.55 ; 95 \% \mathrm{CI}, 2.56-8.10)$, and more than eight times for the oldest age group of $95+$ years $(\mathrm{RR}=8.54 ; 95 \%$ CI, 4.67-15.60; Table 3).

Sensitivity analysis of 2,349 acute hip fracture patients

For sensitivity analysis, we combined data from three major hospital centers in Zurich. The results of the sensitivity analysis are presented in Table 4. Notably, extending the study population to 2,349 seniors with acute hip fracture, the results 
Table 3 Primary analysis: unadjusted and adjusted associations of important risk factors with risk of hip fracture $(n=1,084)$

\begin{tabular}{|c|c|c|c|c|c|c|}
\hline \multirow[t]{3}{*}{ Characteristic } & \multicolumn{6}{|l|}{ Rate ratio $(95 \% \mathrm{CI})$} \\
\hline & \multicolumn{2}{|l|}{ Unadjusted } & \multirow[t]{2}{*}{$p^{\mathrm{a}}$ value } & \multirow[b]{2}{*}{ Community dwelling } & \multirow{2}{*}{$\begin{array}{l}\text { Adjusted }^{\mathrm{b}} \\
\text { Institutionalized }\end{array}$} & \multirow[t]{2}{*}{$p$ value } \\
\hline & Community dwelling & Institutionalized & & & & \\
\hline \multicolumn{7}{|l|}{ Gender } \\
\hline Women & $2.35(1.21-4.57)$ & $0.86(0.40-1.87)$ & 0.06 & $2.16(1.74-2.69)$ & $0.77(0.63-0.95)$ & $<0.0001$ \\
\hline Men (Ref.) & - & - & & - & - & \\
\hline \multicolumn{7}{|l|}{ Season } \\
\hline Fall & $0.88(0.38-2.04)$ & $1.02(0.37-2.81)$ & 0.99 & $0.87(0.71-1.06)$ & $1.02(0.81-1.28)$ & 0.65 \\
\hline Winter & $0.94(0.41-2.15)$ & $0.98(0.35-2.72)$ & & $0.95(0.79-1.14)$ & $1.01(0.80-1.27)$ & \\
\hline Spring & $0.91(0.39-2.09)$ & $0.84(0.29-2.43)$ & & $0.89(0.74-1.09)$ & $0.88(0.69-1.11)$ & \\
\hline Summer (Ref.) & - & - & & - & - & \\
\hline \multicolumn{7}{|l|}{$\mathrm{Age}^{\mathrm{c}}$} \\
\hline 65-74 (Ref.) & - & - & 0.002 & - & - & $<0.0001$ \\
\hline $75-84$ & $5.89(4.16-8.33)$ & $2.69(1.29-5.59)$ & & $5.60(4.42-7.09)$ & $2.78(1.51-5.10)$ & \\
\hline $85-94$ & $16.21(11.34-23.17)$ & $4.28(2.10-8.73)$ & & $15.20(11.98-19.28)$ & $4.55(2.56-8.10)$ & \\
\hline $95+$ & $27.35(13.53-55.26)$ & $7.58(3.50-16.40)$ & & $22.14(13.57-36.14)$ & $8.54(4.67-15.60)$ & \\
\hline
\end{tabular}

${ }^{\mathrm{a}} p$ value compares rate ratios in community-dwelling seniors against that in institutionalized seniors

${ }^{\mathrm{b}}$ Adjusted for season, age, gender, type of dwelling, Mini Mental Score, and comorbidities (Charlson comorbidity index). Data from six people were excluded from the adjusted model due to missing MMSE scores (sample size for the adjusted model $N=1,078$ )

${ }^{\mathrm{c}}$ Sample sizes of age categories $65-74$ (community-dwelling $n=73$, institutionalized $\left.n=15\right) ; 75-84$ (community-dwelling $n=317$, institutionalized $n=$ 121); 85-94 (community-dwelling $n=242$, institutionalized $n=238)$; 95+ (community-dwelling $n=18$, institutionalized $n=60$ )

were not materially different from those of the primary analysis. As in the primary analysis, the effect of gender on hip fracture risk differed by type of dwelling: Among communitydwelling seniors hip fracture rates were $65 \%$ higher in women compared with men ( $\mathrm{RR}=1.65,95 \% \mathrm{CI}, 1.51-1.80)$. The somewhat reduced gender difference among communitydwelling seniors may be explained by the reduced number of confounders that could be considered in this extended data set. Among institutionalized seniors, women had $20 \%$ lower rate of hip fracture compared with men $(R R=0.80$, $95 \%$ CI, 0.68-0.95). Average age- and season-adjusted rates for community-dwelling and institutionalized men and women are presented in Fig. 1a and b for both the primary and the sensitivity analysis. Also, consistent with the primary analysis, there was no seasonal swing of hip fracture risk (Table 4, Fig. 2b), and higher age remained a strong and independent risk factor for hip fracture risk. Consistent with the primary analysis, the effect of age was stronger in community-dwelling seniors than in those living in institutions (Table 4).

\section{Discussion}

In this study of acute hip fracture patients age 65 years and older, we show that hip fracture rates differ by gender between community-dwelling seniors and seniors residing in nursing homes. While we confirm that women have a significantly higher rate of hip fracture among the community-dwelling senior population, we document the opposite among institutionalized seniors. Among seniors residing in nursing care, men had a higher rate of hip fracture compared with women. This finding was significant in the primary analysis among 1,084 seniors with a $23 \%$ lower rate of hip fracture among institutionalized women compared with institutionalized men independent of age, season, comorbid conditions, and cognitive function, and confirmed in our sensitivity analysis among 2,349 seniors with a $20 \%$ lower rate of hip fracture among institutionalized women compared with institutionalized men. Regarding our second goal, to determine whether hip fracture rates in seniors residing in the Zurich area of Switzerland vary with season, we found no such indication in either the primary or the sensitivity analysis.

Our study confirms many earlier studies among communitydwelling seniors showing that hip fracture rates are 1.5-3 times higher among women compared with men $[5,10,12-14,18$, $21,25,47,49,66]$. However, our study also contributes to an area less well studied, the gender-specific hip fracture rates in institutionalized seniors. Sugarman et al. assessed data from American seniors collected between 1993 and 1995 and found that while hip fracture risk was 2.4-fold higher among 
Fig. 1 a Adjusted fracture incidence rates (per 1,000 personyears) in men and women by living conditions (primary analysis, $N=1,084)$. b Adjusted fracture incidence rates (per 1,000 person-years) in men and women by living conditions (sensitivity analysis, $N=2,349$ ) a

30 25

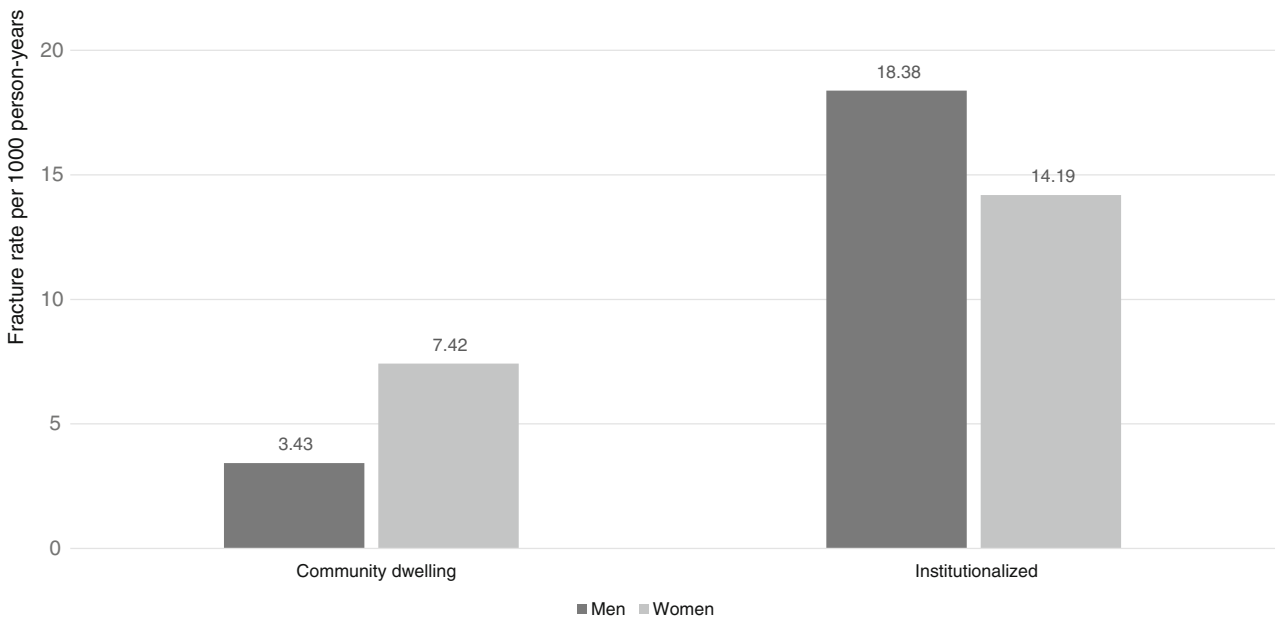

b

30

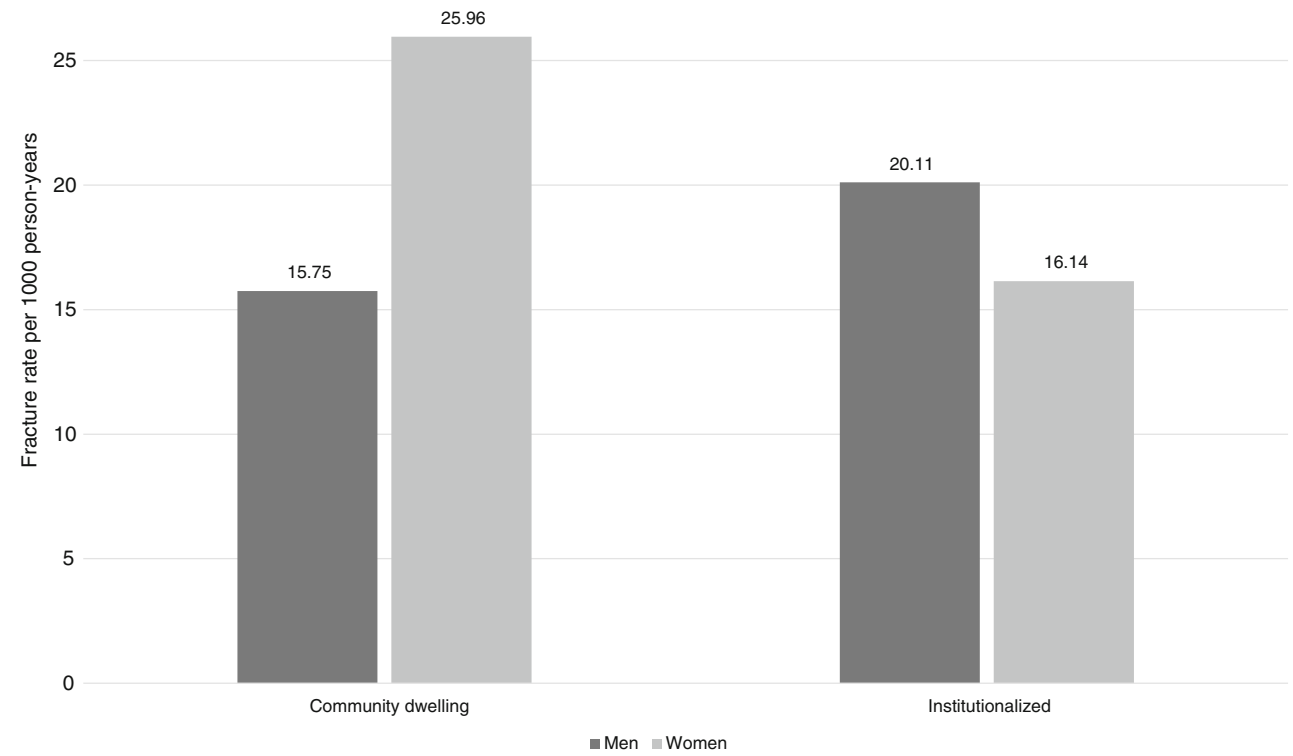

community-dwelling women compared with communitydwelling men, there was no gender difference in hip fracture rates among nursing home residents [47].

To our knowledge, our study is the first to report that hip fracture rates may be significantly higher among institutionalized men compared with institutionalized women. Our findings may in part be explained by the combination of fall and fracture prevention strategies that are targeted more at women and the fact that institutionalized men tend to be frailer and have more comorbidities compared with women. According to the literature, community dwelling women are viewed as the gender at risk $[67,68]$. This leads to preventive strategies being targeted predominantly at women lowering their fracture rates. On the other hand, senior men living in nursing homes may be frailer and have more comorbidity compared with women, which could contribute to their higher fracture 
Fig. 2 a Number of hip fractures by weeks of the year (primary analysis population, $N=1,084$ ). b: Number of hip fractures by weeks of the year (sensitivity analysis population, $N=2,349$ ) a 70

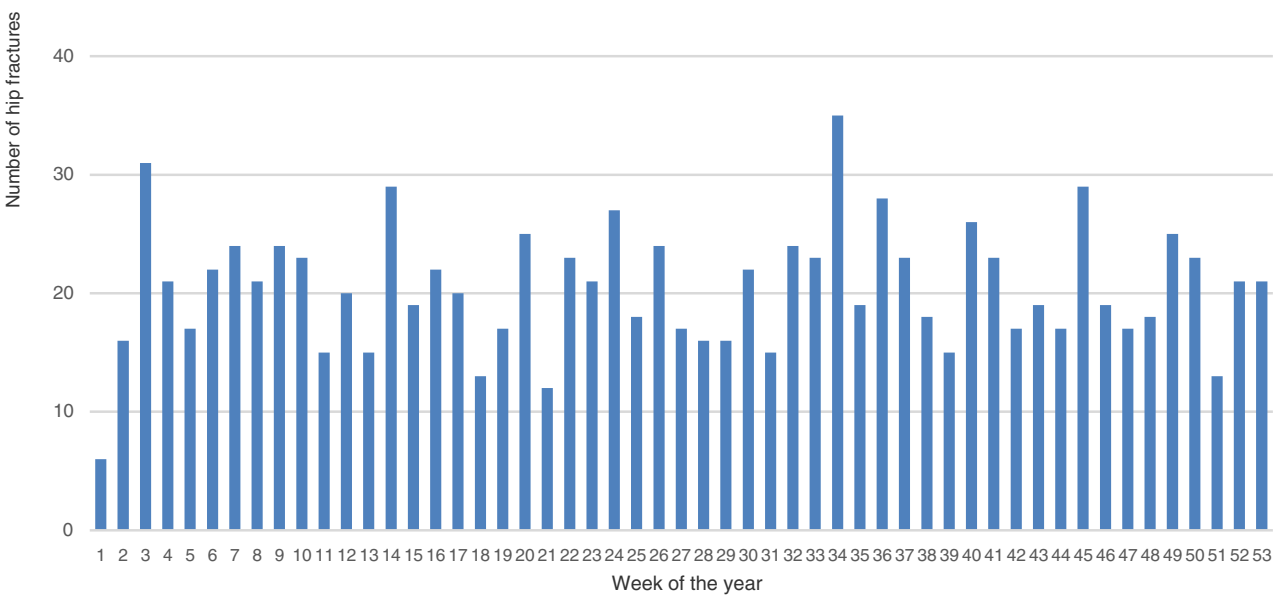

b

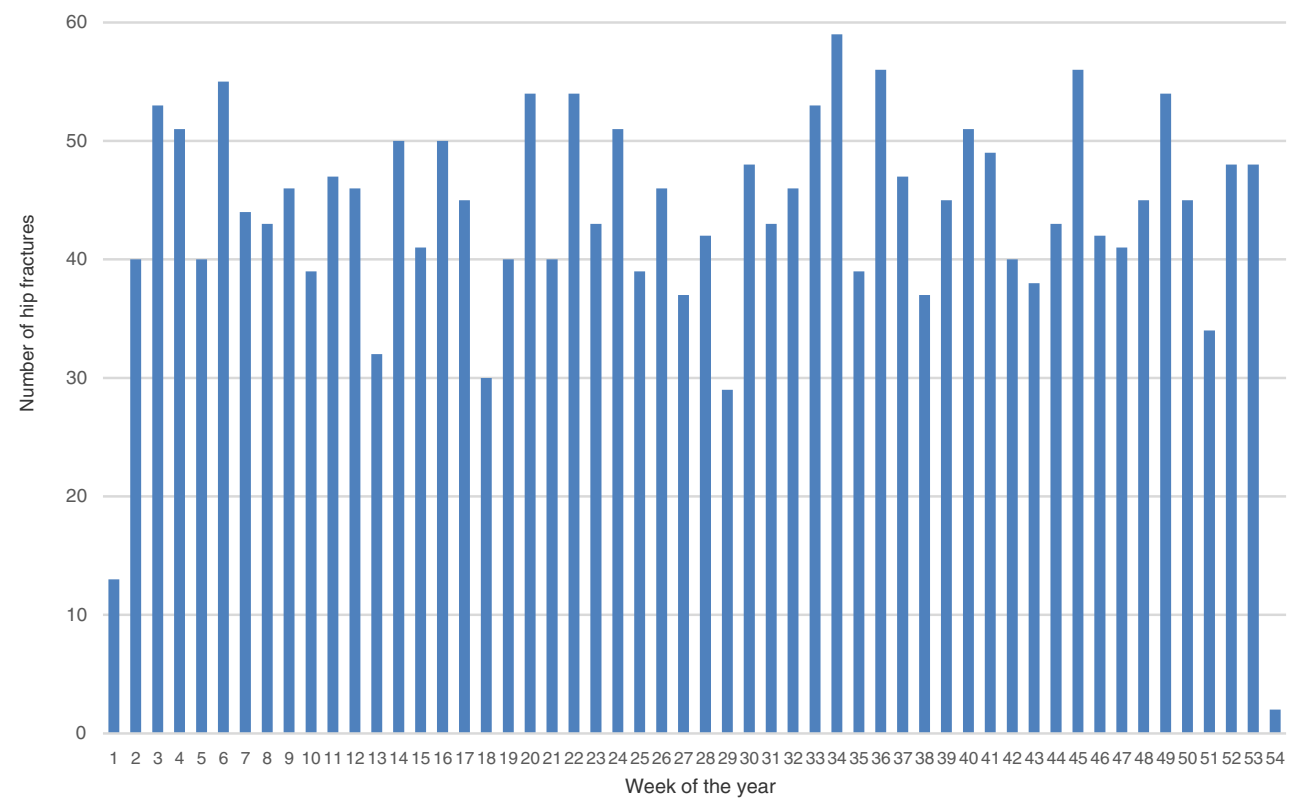

rates. Several studies found that mortality in the first year after hip fracture is up to three times higher in men compared with women $[69,70]$.

In our earlier analysis in a population-based sample of US Medicare recipients age 65 years and older, there was a striking difference in seasonality patterns of forearm and humerus fractures versus hip fractures, with forearm and humerus fractures showing a pronounced seasonal swing and hip fractures only a very small increase in the winter compared with the summer season [30]. Consistently, in this study of Swiss seniors, hip fracture rates did not change with season, independent of age, type of dwelling prior to the 
Table 4 Sensitivity analysis: unadjusted and adjusted associations of important risk factors with risk of hip fracture $(N=2,349)$

\begin{tabular}{|c|c|c|c|c|c|c|}
\hline \multirow[t]{3}{*}{ Characteristic } & \multicolumn{6}{|l|}{ Rate ratio $(95 \% \mathrm{CI})$} \\
\hline & \multicolumn{2}{|l|}{ Unadjusted } & \multirow[t]{2}{*}{$p$ value $^{\mathrm{a}}$} & \multicolumn{2}{|l|}{ Adjusted $^{\mathrm{b}}$} & \multirow[t]{2}{*}{$p$ value } \\
\hline & Community dwelling & Institutionalized & & Community dwelling & Institutionalized & \\
\hline \multicolumn{7}{|l|}{ Gender } \\
\hline Women & $1.99(1.02-3.87)$ & $0.91(0.25-3.36)$ & 0.32 & $1.65(1.51-1.80)$ & $0.80(0.68-0.95)$ & $<0.0001$ \\
\hline Men (ref.) & - & - & & - & - & \\
\hline \multicolumn{7}{|l|}{ Season } \\
\hline Fall & $1.01(0.42-2.41)$ & $1.01(0.20-5.13)$ & 1.00 & $1.01(0.91-1.12)$ & $1.05(0.86-1.27)$ & 0.41 \\
\hline Winter & $1.04(0.44-2.47)$ & $0.90(0.17-4.79)$ & & $1.04(0.93-1.15)$ & $0.93(0.76-1.14)$ & \\
\hline Spring & $1.01(0.42-2.41)$ & $0.86(0.16-4.68)$ & & $1.01(0.91-1.12)$ & $0.89(0.73-1.09)$ & \\
\hline Summer (ref.) & - & - & & - & - & \\
\hline \multicolumn{7}{|l|}{$\mathrm{Age}^{\mathrm{c}}$} \\
\hline 65-74 (Ref.) & - & - & $<0.0001$ & - & - & $<0.0001$ \\
\hline $75-84$ & $5.02(3.96-6.38)$ & $2.92(1.33-6.42)$ & & $4.92(4.34-5.59)$ & $2.95(1.94-4.48)$ & \\
\hline $85-94$ & $19.29(15.23-24.44)$ & $4.74(2.20-10.21)$ & & $18.40(16.22-20.86)$ & $4.86(3.23-7.31)$ & \\
\hline $95+$ & $57.12(40.38-80.79)$ & $7.58(3.28-17.47)$ & & $53.11(44.17-63.86)$ & $7.89(5.05-12.30)$ & \\
\hline
\end{tabular}

${ }^{a} p$ value compares rate ratios in community-dwelling seniors against that in institutionalized seniors

${ }^{\mathrm{b}}$ Adjusted for season, age, gender, and type of dwelling

${ }^{\mathrm{c}}$ Sample sizes of age categories 65-74 (community-dwelling $n=200$, institutionalized $n=16$ ); 75-84 (community-dwelling $n=741$, institutionalized $n=$ 140); 85-94 (community-dwelling $n=789$, institutionalized $n=281$ ); $95+$ (community-dwelling $n=118$, institutionalized $n=64$ )

fracture event, gender, and cognitive function. One plausible explanation may be found in the circumstances surrounding these fractures. Hip fractures tend to occur indoors among relatively frail individuals [55-57], who are less likely to be outdoors in the snow. However, as mentioned in the "Introduction" section, winter season may influence hip fracture risk indirectly through hypothermia $[55,58]$, reduced physical activity[60], and vitamin D depletion during winter season, which may contribute to muscle weakness $[59,60]$ and increase the risk of falls [61, 62] and fractures [63]. However, as described in an earlier study of 222 acute hip fracture patients from the same large hospital center as those enrolled in our primary analysis, vitamin D deficiency was prominent in all seasons [71].

An important strength of our study is that it had good coverage of hip fracture cases that occurred between January 2005 and March 2010 in Zurich. The detailed data on 1,084 patients used for the primary analysis came from one large hospital center in Zurich, and the combined data set used for the sensitivity analysis extended to the other two large hospital centers in Zurich. Furthermore, the population of Zurich increased by about $4 \%$ between 2002 and 2010; thus, 2002 population statistics provided good estimates for the source population. Furthermore, the consistency between the primary and the sensitivity analysis contributes to the strength of our findings. Another strength of our analyses is the inclusion of important covariates that influence hip fracture risk: age, season, comorbid conditions, and cognitive function. A possible limitation of our study may be an underestimation of the source population size. All three hospitals that provided data for the study serve as referral centers for the entire Zurich agglomeration, which, besides the city itself, also includes nearby communities. However, the population of Zurich agglomeration tends to be similar to the one of the City of Zurich, which means that the ratio measures are likely to be unaffected. Population of seniors living in nursing homes or other assisted living facilities may differ substantially from one country to the next due to different health care systems and rules and regulation governing admission of senior to such institutions. This means that our results may not be readily generalizable to other countries.

In summary, our results show that gender-specific hip fracture rates differ depending on type of dwelling. While senior women are at greater risk of hip fracture while they live in the community, senior men are at greater risk in the institutionalized setting. Our findings are relevant to clinical practice suggesting that, next to senior women, senior men also need to be targeted in the prevention of falls and hip fractures. As hip fracture rates did not change with season in our study, such efforts may be warranted throughout the year.

Conflicts of interest None. 


\section{References}

1. Guccione AA et al (1994) The effects of specific medical conditions on the functional limitations of elders in the Framingham Study. Am J Public Health 84(3):351-358

2. Birge SJ, Morrow-Howell N, Proctor EK (1994) Hip fracture. Clin Geriatr Med 10(4):589-609

3. Giusti A et al (2008) Predictors of hospital readmission in a cohort of 236 elderly discharged after surgical repair of hip fracture: one-year follow-up. Aging Clin Exp Res 20(3):253-259

4. Magaziner J et al (2000) Recovery from hip fracture in eight areas of function. J Gerontol A Biol Sci Med Sci 55(9):M498-M507

5. Cummings SR et al (1985) Epidemiology of osteoporosis and osteoporotic fractures. Epidemiol Rev 7:178-208

6. Boockvar KS et al (2003) Hospital readmissions after hospital discharge for hip fracture: surgical and nonsurgical causes and effect on outcomes. J Am Geriatr Soc 51(3):399-403

7. Bischoff-Ferrari HA et al (2010) Effect of high-dosage cholecalciferol and extended physiotherapy on complications after hip fracture: a randomized controlled trial. Arch Intern Med 170(9):813-820

8. Adams AL, et al (2012) Ten-year hip fracture incidence rate trends in a large California population, 1997-2006. Osteoporos Int

9. Brauer CA et al (2009) Incidence and mortality of hip fractures in the United States. JAMA 302(14):1573-1579

10. Chang KP et al (2004) Incidence of hip and other osteoporotic fractures in elderly men and women: Dubbo Osteoporosis Epidemiology Study. J Bone Miner Res 19(4):532-536

11. Dimai HP et al (2011) Epidemiology of hip fractures in Austria: evidence for a change in the secular trend. Osteoporos Int 22(2): 685-692

12. Alvarez-Nebreda ML et al (2008) Epidemiology of hip fracture in the elderly in Spain. Bone 42(2):278-285

13. Jaatinen PT et al (2007) Incidence of hip fractures among the elderly in Satakunta, Finland. Scand J Surg 96(3):256-260

14. Lofthus $\mathrm{CM}$ et al (2001) Epidemiology of hip fractures in Oslo, Norway. Bone 29(5):413-418

15. Kannus $P$ et al (2006) Nationwide decline in incidence of hip fracture. J Bone Miner Res 21(12):1836-1838

16. Kannus $P$ et al (1999) Hip fractures in Finland between 1970 and 1997 and predictions for the future. Lancet 353(9155):802-805

17. Kannus P et al (1996) Epidemiology of hip fractures. Bone 18(1 Suppl):57S-63S

18. Kanis JA (1993) The incidence of hip fracture in Europe. Osteoporos Int 3(Suppl 1):10-15

19. Hernandez JL et al (2006) Trend in hip fracture epidemiology over a 14-year period in a Spanish population. Osteoporos Int 17(3):464 470

20. Lofman O et al (2002) Changes in hip fracture epidemiology: redistribution between ages, genders and fracture types. Osteoporos Int 13(1):18-25

21. Brennan nee Saunders J et al (2003) Place of residence and risk of fracture in older people: a population-based study of over 65-yearolds in Cardiff. Osteoporos Int 14(6):515-519

22. Cumming RG (1996) Nursing home residence and risk of hip fracture. Am J Epidemiol 143(12):1191-1194

23. Hokby A, Reimers A, Laflamme L (2003) Hip fractures among older people: do marital status and type of residence matter? Public Health 117(3):196-201

24. Norton R et al (1999) Residential status and risk of hip fracture. Age Ageing 28(2):135-139

25. Ooms ME et al (1994) The incidence of hip fractures in independent and institutionalized elderly people. Osteoporos Int 4(1):6-10

26. Mussolino ME et al (1998) Risk factors for hip fracture in white men: the NHANES I Epidemiologic Follow-up Study. J Bone Miner Res 13(6):918-924
27. Johnell O et al (1995) Risk factors for hip fracture in European women: the MEDOS Study. Mediterranean Osteoporosis Study. J Bone Miner Res 10(11):1802-1815

28. Kanis J et al (1999) Risk factors for hip fracture in men from southern Europe: the MEDOS study. Mediterranean Osteoporosis Study. Osteoporos Int 9(1):45-54

29. Cummings-Vaughn LA, Gammack JK (2011) Falls, osteoporosis, and hip fractures. Med Clin N Am 95(3):495-506

30. Bischoff-Ferrari HA et al (2007) Effect of seasonality and weather on fracture risk in individuals 65 years and older. Osteoporos Int 18(9): $1225-1233$

31. Bulajic-Kopjar M (2000) Seasonal variations in incidence of fractures among elderly people. Inj Prev 6(1):16-19

32. Chiu KY, Ng TP, Chow SP (1996) Seasonal variation of fractures of the hip in elderly persons. Injury 27(5):333-336

33. Crawford JR, Parker MJ (2003) Seasonal variation of proximal femoral fractures in the United Kingdom. Injury 34(3):223-225

34. Douglas S et al (2000) Seasonal variation of hip fracture at three latitudes. Injury 31(1):11-19

35. Gronskag $A B$ et al (2010) Incidence and seasonal variation in hip fracture incidence among elderly women in Norway. The HUNT Study. Bone 46(5):1294-1298

36. Hemenway D, Colditz GA (1990) The effect of climate on fractures and deaths due to falls among white women. Accid Anal Prev 22(1):59-65

37. Jacobsen SJ et al (1991) Seasonal variation in the incidence of hip fracture among white persons aged 65 years and older in the United States, 1984-1987. Am J Epidemiol 133(10):996-1004

38. Jacobsen SJ et al (1995) Population-based study of the contribution of weather to hip fracture seasonality. Am J Epidemiol 141(1):79-83

39. Lau EM et al (1995) The seasonality of hip fracture and its relationship with weather conditions in New South Wales. Aust J Public Health 19(1):76-80

40. Levy AR et al (1998) Inclement weather and the risk of hip fracture. Epidemiology 9(2):172-177

41. Lin HC, Xiraxagar S (2006) Seasonality of hip fractures and estimates of season-attributable effects: a multivariate ARIMA analysis of population-based data. Osteoporos Int 17(6):795-806

42. Mirchandani S et al (2005) The effects of weather and seasonality on hip fracture incidence in older adults. Orthopedics 28(2):149-155

43. Turner RM et al (2011) Air temperature and the incidence of fallrelated hip fracture hospitalisations in older people. Osteoporos Int 22(4):1183-1189

44. Chesser TJ et al (2002) The influence of outside temperature and season on the incidence of hip fractures in patients over the age of 65 . Age Ageing 31(5):343-348

45. Parker MJ, Martin S (1994) Falls, hip fractures and the weather. Eur J Epidemiol 10(4):441-442

46. Pedrazzoni M et al (1993) Seasonal variation in the incidence of hip fractures in Emilia-Romagna and Parma. Bone 14(Suppl 1):S57-S63

47. Sugarman JR et al (2002) Hip fracture incidence in nursing home residents and community-dwelling older people, Washington State, 1993-1995. J Am Geriatr Soc 50(10):1638-1643

48. Rudman IW, Rudman D (1989) High rate of fractures for men in nursing homes. Am J Phys Med Rehabil 68(1):2-5

49. Butler $\mathrm{M}$ et al (1996) The risks of hip fracture in older people from private homes and institutions. Age Ageing 25(5):381-385

50. Graafmans WC et al (1996) Different risk profiles for hip fractures and distal forearm fractures: a prospective study. Osteoporos Int 6(6): $427-431$

51. Tenias JM et al (2009) Short-term relationship between meteorological variables and hip fractures: an analysis carried out in a health area of the Autonomous Region of Valencia, Spain (1996-2005). Bone 45(4):794-798

52. Ralis ZA (1981) Epidemic of fractures during period of snow and ice. Br Med J (Clin Res Ed) 282(6264):603-605 
53. O'Neill TW et al (1996) Risk factors, falls, and fracture of the distal forearm in Manchester, UK. J Epidemiol Community Health 50(3): 288-292

54. Keegan TH et al (2004) Characteristics of fallers who fracture at the foot, distal forearm, proximal humerus, pelvis, and shaft of the tibia/ fibula compared with fallers who do not fracture. Am J Epidemiol 159(2): 192-203

55. Nevitt MC, Cummings SR (1994) Type of fall and risk of hip and wrist fractures: the study of osteoporotic fractures. J Am Geriatr Soc 42(8):909

56. Carter SE et al (2000) Accidents in older people living at home: a community-based study assessing prevalence, type, location and injuries. Aust N Z J Public Health 24(6):633-636

57. Campbell AJ et al (1990) Circumstances and consequences of falls experienced by a community population 70 years and over during a prospective study. Age Ageing 19(2):136-141

58. Bastow MD, Rawlings J, Allison SP (1983) Undernutrition, hypothermia, and injury in elderly women with fractured femur: an injury response to altered metabolism? Lancet 1(8317):143-146

59. Bischoff-Ferrari HA (2011) Relevance of vitamin D in muscle health. Rev Endocr Metab Disord 13:71-77

60. Theiler R et al (2000) Influence of physical mobility and season on 25-hydroxyvitamin D-parathyroid hormone interaction and bone remodelling in the elderly. Eur J Endocrinol 143(5):673-679

61. Bischoff-Ferrari HA et al (2009) Fall prevention with supplemental and active forms of vitamin D: a meta-analysis of randomised controlled trials. BMJ 339(1):339-b3692
62. Bischoff-Ferrari HA, et al (2011) Re: Fall prevention with vitamin D. Clarifications needed. http://www.bmj.com/content/339/bmj.b3692? tab=responses (access: Feb13.2012)

63. Bischoff-Ferrari HA, et al (2012) A pooled analysis of vitamin D dose requirements for fracture prevention. N Engl J Med 367:40-49; July 5th 2012

64. Charlson ME et al (1987) A new method of classifying prognostic comorbidity in longitudinal studies: development and validation. J Chron Dis 40(5):373-383

65. Folstein MF, Folstein SE, McHugh PR (1975) "Mini-mental state". A practical method for grading the cognitive state of patients for the clinician. J Psychiatr Res 12(3):189-198

66. Elffors I et al (1994) The variable incidence of hip fracture in southern Europe: the MEDOS Study. Osteoporos Int 4(5):253-263

67. Feldstein AC et al (2005) The near absence of osteoporosis treatment in older men with fractures. Osteoporos Int 16(8):953-962

68. Chevalley $\mathrm{T}$ et al (2007) Incidence of hip fracture over a 10-year period (1991-2000): reversal of a secular trend. Bone 40(5):1284-1289

69. Center JR et al (1999) Mortality after all major types of osteoporotic fracture in men and women: an observational study. Lancet 353(9156):878-882

70. Lu-Yao GL et al (1994) Treatment and survival among elderly Americans with hip fractures: a population-based study. Am J Public Health 84(8):1287-1291

71. Bischoff-Ferrari HA et al (2008) Severe vitamin D deficiency in Swiss hip fracture patients. Bone 42(3):597-602 